\title{
Occasional words Speech Unit
}

\author{
O.Y. Tukhtasinova \\ ${ }^{I}$ Ph.D, Associate Professor of Kokand state pedagogical institute, \\ Email:tukhtasinova@umail.uz
}

\begin{abstract}
Abstract: This article discusses the study of occasional words in Russian and Uzbek linguistics, the features of occasional words: dependence on speech (text), creativity, perception of correct or incorrect occasional words, the relationship between occasional word and language norm, one-time use of occasional words. A word is an expressive, optional nomenclature, a synchronous and diachronic mixture of occasional words.
\end{abstract}

Keywords: occasionalism, artistic occasionalism, word, speech specificity, disposition, deviation, based on word formation, abnormality, expression, nominativity, synchronous diachronic confusion, individuality.

\section{INTRODUCTION}

The language is constantly enriched with new vocabulary units. Words are not born without communicative necessity. However, newly formed words vary depending on their language position. Any newly formed language units may or may not have their place in the language system. The dictionary contains words that are unique to the person, and which remain only in the context of speech (text). Such words are created by the people or linguists. In linguistics, folk words are called oral occasionalism, and words created by some creators of fiction are characterized as individual speech, that is, artistic occasionalism.

Occasional words are created by speakers or creators of works of art to express their thoughts and intentions in a clear and accurate form, to present all aspects of a person, things, objects and events that they depict, and to express their feelings and feelings towards them. Occasionalism is created when the possibilities of the language in the description of the image object cannot satisfy the speaker.

The study of the processes of formation and development of the vocabulary of the language has its own history. Occasional words pay attention to the work on this issue. In Russian linguistics, the study of occasional words from neologisms began in the 1950s. In Russian linguistics N.I. Feldman was the first to use the term occasionalism. He interprets occult expressions as linguistic units that arise from productive types of word formation and have a specific textual meaning [1]. The dissertation of Ernest Khanpir was devoted to the study of occasionalism inherent in the work of V. Mayakovsky was his first monographic work [2].

A.Mamatov studied the Uzbek language in the context of the relation of occasional words to the literary norm. He also identifies speech specificity as one of the main features of occasional words and argues that one of the key features of their creation is the variety of speech. The researcher shows seven signs of Uzbek occasional words. These are: 1) relativity to speech; 2) abnormality, 3) one-time use; 4) created by speakers or writers; 5) expressivity; 6) compliance with the rules of word formation; 7) historical and modern adaptation [3]. The researcher does not take into account the nominative elements in this. In our opinion, occasional words are characteristic, since they are also the names of objects objects, events and actions. For example, kumzor (sandy field), yozlok (summer place), g'ozapoyaxokim (cotton stalk governor), futbolgoh (football field), kishboy (thick-dressed man), xo'pchi (man who always says yes), hazilvon to expresses a place or person.

S. Muminov compares neologism and occasionalism and shows their characteristic features. It lists the important features of occasionalism: 1) the relationship of occasionalism to the glossary layer; 2) individuality (occasional value); 3) a one-time speech unit, often with an emotional and expressive dye; 4) service for a certain artistic state of speech; 5) motivation [4]. 
Of the above signs, the motivation for occasionalism is not distinguished by other researchers. S. Muminov took the fifth element as the basis of his work.

S. Tashalieva in her Ph.D. thesis on the topic "Creating Occasional Words in Uzbek Language" lists the following, as features of occasional words: 1) text and speech situations; 2) abnormality-immensity; 3) one-time use; 4) personal creativity - words related to creativity; 5) attitude to word formation and use of the word; 6) the educational process, educational style, reason for use; 7) ordinary and unusual relationships associated with the separation of the morpheme and composition; 8) for application and education, a certain unit (microtext) is required; 9) associated with certain language-subconscious images and changes; 10) is a method for naming speech and generating text [5].

Other researchers did not specify the nature of occasionalism. They simply emphasized the role of occasionalism in expressing a particular creator.

In the previous part of our work, we identified the difference between neologism and occasionalism, as far as possible, based on our observations and analyzed the characterization of occasionalism. We list them below: 1) synchronously-diachronic mixing; 2) the existence of the author; 3) a measure of novelty; 4) the appearance and non-appearance of language as part of the dictionary. These signs are signs that distinguish occasionalism from neologism. The most important sign of occasionalism when approaching from this point of view is their relation to time, that is, the principle that they do not become obsolete and remain as a new word.

Regarding other features, we would like to express an opinion based on the analysis of factual material and on the basis of the opinion of the aforementioned scientists. Occasional words created and located in a specific fragment of speech find themselves in the most active zone of interaction between language and speech. On the one hand, they represent a conflict between linguistic and speech facts, and on the other, they also represent contradictions between the linguistic system and the norm. Although such words are used in the course with other words (interchangeable words), they differ only in their features. It:

\section{SPEECH DEPENDENCE ON THE TEXT.}

This symptom is the most important sign of occasional words. In this speech situation, there are such units of speech that are more meaningful and more emotional than a simple language unit, which is created and used in the text to which they belong and with which they live. It is not necessary that such words be included in the vocabulary and transferred for general use.

The units included in a particular linguistic vocabulary are stable words and their relative dependence on the text. Because stable words can be used separately in speech, in monosyllabic sentences in verbal and non-verbal expressions. The dependence of occasional words on the text is often necessary, and they cannot live separately from the text. The lexical meaning of an occasional word (for example, uvadaband, kuzaytirmoq, damkash, sezim, nursiramoq, rangdosh) obtained from the text is likely to be interpreted as a likely characteristic that allows using this word together with ordinary words in speech.

Therefore, although a stable word depends on the text, it itself assumes and forms it. In other words, a stable word is an active factor in the creative formation of a text. And an occasional word does not have the ability to create its own text. For example: We are a spiritual organization — “Ranjkom” , that is, it is our job to offend others. (A.Oripov) (Biz manaviy tashkilotmiz - "Ranzhkom" miz, yani uzgalarni ranzhitmoqlik bizning ishimiz. (A.Oripov)

The word ranking in this text has no meaning and is incomprehensible, not relying on a much wider text of stable words.

\section{CREATIVITY}

The creativity of occasional words resists the resonance of everyday words. When common words are called stagnant, their memory is restored, that is, they are easily accessible in the dictionary and are used functionally (repeatedly). Perhaps a normal word refers to the form and meaning of a language in a dictionary that is used in speech based on specific skills and qualifications. In this they are used in form and meaning.

The use of occasional words is not the memorization of the finished form or meaning, but the creation of a new word. Each use of such words is new. 
In fact, an occasional word must be derivative, because at least it is the result of a relatively free combination of two morphemes. An occasional word is not always created; it is the result of a speech need, an urgent need. Therefore, such words are rare in speech and not common in the language of any creative person. The creation of such words requires a certain inventiveness and skill from the writer.

3. The relationship between the occasional word and the norm. The creation of occasional words to a certain extent is a violation of the lexical-semantic norm of the language. The ratio of occasional words to the norm is not the same. Some occasional words are created in accordance with the existing rules of word formation in the language: Har nechuk, shoirman - sen bilan zhondosh, Tuyingda tuydoshman, tirik yeldosh.... degayman, yosh umring uylab, hey, kondosh, Bitgum, bitilmagan dostoning menda (A.Oripov). In this passage, satirical occasionalism tuidosh does not differ from the words kondosh, jondosh, yelkadosh. However, it differs from these words, firstly, in terms of use, and secondly, by the author. This word, like the basic elements of the language, is a non-standard unit of speech in dictionaries and grammar.

Although the words asaliston, changiston, balchiston, shovқinzor, and ғпғіrоқzor are based on productive word-formation models, they also violate word-formation rules. The suffix is " understood from the baseline: ".. nouns (crops, trees, etc.) create the name of the place where it is abundant," and "the name of the people (nation) or any other word makes a noun in the sense of that place, where it is most used "[6]. But the following examples show a violation of this rule: O Uzbekistan, my chest with honey, my honey. (O. Majon) In the summer and dusty winter in Balkhash. (E. Vakhidov) No one will notice that I ascended the throne. Once I went through this noise. (H. Khudoiberdieva) Complaints of the world are a telephone and an alarm with cold wires. (N. Norkabul)

By language criteria, the affixes -on and -iston are added to words that represent living, growing things, but in the above examples they create new words from words that are something inanimate and represent many of them. However, a large number of such things are represented by analytical forms. Compare: asali kup Uzbekiston - asaliston Uzbekistan, changib yotadigan kucha - changiston kucha, balchik buladigan kuch - balchigiston kucha, shovkin-suron (dunyo) - shovkinzor (dunyo), doim kungirok ovozlari eshitiladigan hona kungirokzor.

The analogy is that such occasionalism is a violation of the principle of word formation, but pleasant for the reader or listener. This is because, firstly, the need for compactness is met, and on the other hand, a beautiful image is obtained.

In the modern Uzbek language, there are a number of additives that have reduced their productivity. For example, the suffixes -us, -shash, -world are exciting elements of the original PersianTajik language and currently do not create new words. But in their presence there are such words of the author as havohur, gurbatkash, sherfurush, mansabfurush, balokash. Such words are not normal. That is why they seem strange. But this is justified by hostility, inaccuracy and is subject to a specific goal. Examples: Deylik, Los Angeles shahri ustiga kora kanot yoydi motorlar dudi. Tokyo, London, New .. Kurum bosgach, kuk - Havokhur bir kalhat, ofat hudhudi (For example, the engines of the Black Wings spread over Los Angeles. Tokyo, London, New York .. "After the drought, the blue - An airy hawk, a disaster zone ) (O. Matczon) ... Uzok buldi bu gurbatkash umrim. Kurdim goh sherfurush, goho sur mansabfurush. (E. Vohidov). As you can see from the examples, occasional words are similar to the text above and cannot be replaced by another word. In this sense, the connection of occasional words with the norm of the language appears on the other hand.

4. Perception of right or wrong occasional words. It is well known that perceptions of occasionalism are correct when they perceive spelling, grammatical and methodological errors as a result of ignorance of language rules.

It seems that occasional words are incorrect because of their most important functional qualities "predetermined" sensitivity and specific semantics. Sometimes speaking words represent a certain skill of the speaker (author) as a created unit, thus losing the listener's skepticism in the ability to speak. The formal incompatibility of occasional words is "justified" because of its functionality and information content. Even if some errors are not the result of illiteracy, they serve as an illustrative tool for a specific character.

Thus, as long as a violation of the criterion becomes a desirable artistic element, it cannot be regarded as a mistake. 
5. One-time use of occasional words is one of their important features. Use only once in speech and gives a unique character to speech situations. Demonstrates clarity, creativity in expression, originality of the language, requires the mobilization of existing language capabilities in the search.

In linguistics, the name of occasional words "individual words", "new words of the author", "individually-author's neologisms", "stylistic neologisms" or "individual-stylistic neologisms", "text neologisms", "one-time neologisms", "poetic neologisms" or "Poetic neologisms" [7] are associated with these features.

Of these names, which represent the features of occasional words, one-time neologisms can be especially noted. This shows the one-time functionality of occasional words.

Each polysemantic word realizes only one of its meanings in the speech process. It is here that the property of the text as a part of speech and the dependence of the word on the text are expressed. However, the dependence of an occasional word on a text is much stronger than the dependence of a stable word on a text, and it can function only once with the text itself. An occasional word does not express the same meaning after using it only once in a certain text with its meaning.

Neologisms are characterized by a rapid transition to popular vocabulary, easy adaptation of various texts, as well as a rapidly used dictionary and reuse in dictionaries. On the other hand, occasionalism exists only for the text created for it [8] and is one-time only.

6. The sensitivity of occasional words. Word sensitivity is of two types: word sensitivity in relation to the text and internal sensitivity. For example, when it comes to the character of a person, you can say tillo odam. The word tillo sounds impressive in this text. Now let's take the right word: tillo usuk. There is only information in this, there is no sensitivity.

Internal sensitivity does not depend on the text, but on the nature of the word.

If nominativeness for stable words is the main task, obligatory responsiveness for occasional words is characteristic. Not all persistent words are expressive. Most of them are neutral, which is an uncompressed language unit.

The sensitivity of occasional words has an intrinsic character. Although they depend on the text, they are affected by their special nature of internal word formation, an occasional word is purely meaning-dependent and does not come from the text.

Different occasionalisms have different levels of occasionalism and sensitivity. The fewer formal and semantic violations of word formation rules when creating occasional words, the less will be occasionalism and responsiveness of the word, and vice versa. In occasional words he is more sensitive than nominative. They add the impression of speech as a means of action and give it a unique flavor of originality.

7. Optional nomination. This feature is one of the signs of occasional words. The concepts of the whole world are reflected in the lexical meanings of words. A stable word is a historically sealed language unit that reflects a particle of existence. This can be explained by several simplified examples. This is a text explaining the meaning of a particular word in annotated dictionaries outlines a "part of reality" that is reinforced by universal language means. For example, in the Explanatory Dictionary of the Uzbek Language 1. Breastfeeding a child. 2. Figurative meaning: having no life experience, inexperienced, stupid person "we learn from them the lexical meanings of the word" gudak ". This is a nominative coercion of a historically stable word in the social and speech experience of people. The nomenclature of occasional words is not specific. A typical nomination can be expressed in other stable words. For example, the meaning of the occasional word "maymuniyat" can be understood with the help of stable words in the expression "monkey identity".

Alternatively, "zamonsoz" occasionalism can be replaced by a combination of "adaptation to time" created by the words of stable words. Both versions are nominated in a nomination, without expressiveness. But with the words "maymuniyat" and "zamonsoz", the listener reaches an impression, not their nomination, and then the image is reborn. In addition, although the nomenclature of stable words is mandatory for most people, the nomenclature of occasionalism does not have to be public. A person who wants to understand their meaning reads a text with an occasional word or does not read. However, the assignment of stable words is a must for everyone to understand in each case.

8. Synchronous and diachronic diffusion of occasional words. This symptom is the most difficult to detect and is due to the fact that the occasional word is at the intersection of the synchronous and 
diachronic axis of the language system. Therefore, an occasional word is a living expression of the connection between synchronism and diachronism.

Linguists have repeatedly argued that synchronicity is related to diachronism. Synchronism and diachronicity cannot be separated from each other.

\section{OCCASIONAL WORDS ARE BOTH SYNCHRONOUS AND DIACHRONOUS.}

Consequently, synchronous words, such as the systematic relationship of stable words to each other, such as the systematic relationship of stable words to each other, interact with them in terms of word formation, semantic, grammatical and other relationships and, therefore, are created by morphemes in speech, i.e. in process of communication. In other words, functionally formulated words do not "stretch" diagonally, in contrast to a stable word, which is remembered as a specific word in different periods of historical life. Occasional words are so diachronous that they are not restored a second time in speech or in memory. As a result of these words, other speech phenomena are added to the chain of periodic actions (synchronous moment) and are instantaneous.

Simultaneous synchronous dichronomy is characteristic of occasional words and is similar to stable words. Because in stable words, the synchronous and diachronic aspects of their life are relatively independent and independent.

The above characters of occasional words are not the same for all such words. For example, the degree of abnormality and responsiveness in different occasional words varies greatly. The degree of occasionalism may even be close to zero. The less occasionalism, the less likely these two characters are, and vice versa. It should also be borne in mind that it is stable and sometimes a transition occurs between occasional words. The word "Dustparvar" by Gafur Gulam appears in his 1956 collection. In 1964, the word in the newspaper "Soviet Uzbekistan" was reused and included in the dictionary [9].

\section{CONCLUSION}

Therefore, when each of the above characters is taken separately, it is not enough to distinguish an occasional word from other units. Together, they make it possible to clearly distinguish it from all other linguistic units, from other non-codified lexical elements of a common language. Therefore, when describing occasional words, their features must be taken into account.

Thus, an occasional word can be described as follows: occasional words are expressive expressions that combine synchronous diachronicity, abnormality, speech style or nomination, word formation features that occur at the time of communication.

\section{REFERENCES}

1. Feldman N.I. Occasional words and lexicography // Questions of linguistics. - 1957. — No. 4. -p. 66.

2. Hanpira Earth. Occasional word formation Mayakovsky (nominal verbs and participles): Author. dis. cand. filol. sciences. The science. -M .1956.

3. Mamatov A. Problems of lexical and phraseological norms in the modern Uzbek literary language:. dis. ..doc. filol. sciences.- T.: 1991.- p. 203-207.

4. Muminov S.M. "The role of motivation in occasional speech nomination": dissertation abstract Tashkent: $1990 .-$ p. 82 .

5. S. Tashaliev. "Construction of an occasional word in the Uzbek language": abstract of dissertantion. - Tashkent: 1998 .- p. 45-46

6. Tursunov Yu., Mukhtorov Yu., Rakhmatullaev Sh. Modern Uzbek literary language. - Tashkent: Uzbekistan, 1992 .- p. 210.

7. Lopatin VV Christmas words // Neologism and occasional word formation. - M.: Nauka, 1973. p.64.

8. Arjanov A. The law is intelligence // Journalist. - 1968. - No. 3 - p. 30

9. B. Choriev. The poetic language of Gafur Gulam. - Tashkent: Nauka, 1990 .- p 96. 